Electromagnetic and ultrasonic investigations on a Roman marble slab

This article has been downloaded from IOPscience. Please scroll down to see the full text article.

2011 J. Geophys. Eng. 8 S117

(http://iopscience.iop.org/1742-2140/8/3/S11)

View the table of contents for this issue, or go to the journal homepage for more

Download details:

IP Address: 147.163.124.115

The article was downloaded on 29/08/2011 at 14:10

Please note that terms and conditions apply. 


\title{
Electromagnetic and ultrasonic investigations on a Roman marble slab
}

\author{
P Capizzi and P L Cosentino ${ }^{1}$ \\ DiSTeM Department, University of Palermo, Via Archirafi 22, 90123, Palermo, Italy \\ E-mail: patrizia.capizzi@unipa.it and pietro.cosentino@unipa.it
}

Received 1 December 2010

Accepted for publication 13 May 2011

Published 23 August 2011

Online at stacks.iop.org/JGE/8/S117

\begin{abstract}
The archaeological museum of Rome asked our group about the physical consistency of a marble slab (second to third century AD) that recently fell during its travel as part of an exhibition. We decided to use different methodologies to investigate the slab: namely a pacometer (Protovale Elcometer) to individuate the internal coupling pins, and ground-penetrating radar (GPR) $(2000 \mathrm{MHz})$ and ultrasonic $(55 \mathrm{kHz})$ tomographic high-density surveys to investigate the internal extension of all the visible fractures and to search for the hidden ones. For the ultrasonic data, tests were carried out to optimize the inversion parameters, in particular the cell dimensions. The choice of cell size for the inversion process must take into account the size of the acquisition grid and the ray number acquired. We proposed to calculate a minimum Fresnel's radius using the sampling frequency instead of that of the probes. For every methodology used, the quality of the acquired data was relatively high. This was then processed and compared to provide information that was useful for some of the insurance problems of the museum. Later on, the data was processed in depth to see how to improve the data processing and interpretation. Finally, the results of this in-depth study were exposed in detail. Ultrasonic and GPR tomographies show a strong correlation, and in particular, the inhomogeneous areas are located in correspondence to the slab injuries.
\end{abstract}

Keywords: ultrasonic, tomography, GPR, covermeter

\section{Introduction}

A marble slab (second to third century AD, figure 1) from the archaeological museum of Rome (Museo delle Terme di Diocleziano) recently fell down during its travel as part of an exhibition. For to insurance purposes, it was necessary to control the new fractures that were due to the recent accident, and possibly distinguish them from the ancient ones. The sculptured slab (current size $1280 \times 70 \times 9 \mathrm{~cm}$ ), cut at the ends for re-use as an inscription on the rear face, was restored (by assembly of different broken parts and cleaning) in modern times. The macroscopic observation and the presence of different fillings show that mechanical damage is complicated by the presence of tenons or pins located inside the thickness of the slab, which must have acted as a lever during the impact. To obtain a complete picture of

\footnotetext{
1 Author to whom any correspondence should be addressed.
}

the physical conditions of the object, a programme of noninvasive investigations was undertaken to highlight the depth of the injury and the consistency of the material for locating the pins. A 3D topographic relief of the slab was provided by Dart (Silvia Gambardella and C. snc) to support in particular the 3D ultrasonic tomography.

Generally, ultrasonic surveys for non-destructive tests and for the characterization of artefacts is a rather well-established methodology (Asakawa and Kawanka 1993, Binda et al 2003, Blitz and Simpson 1996, Dynes and Lytle 1979, Phillips and Fehler 1991, Sambuelli et al 2011, Santamarina and Fratta 1998). In particular, 3D ultrasonic tomography is a recent technique in the diagnostic study of works of art, and is one of the most powerful among the diagnostic methods for studying the structural continuity of the material (Capizzi et al 2009, Cardarelli and De Nardis 2001). This technique can be performed to evaluate either the velocity (or slowness) parameter or the amplitude attenuation, but the former is 


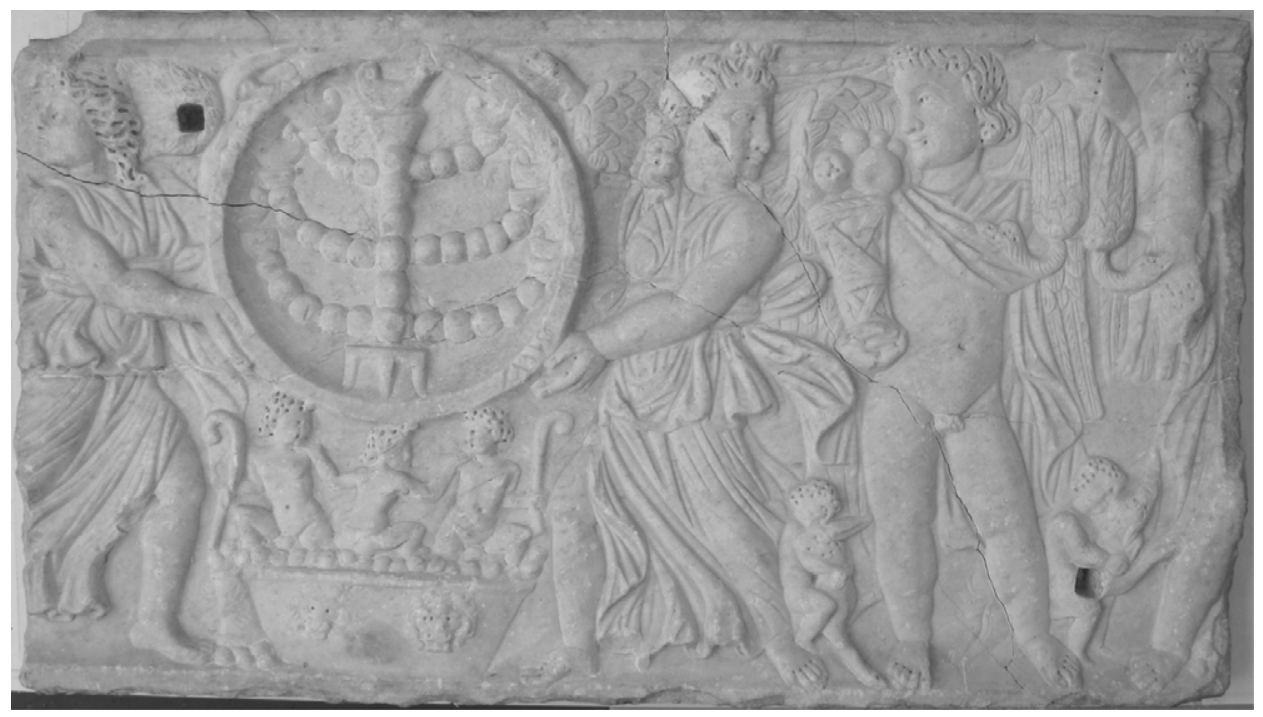

Figure 1. The marble slab (second to third century AD) kept at the archaeological museum of Rome.

almost always preferred for its ease of implementation. In any case, careful choice of the inversion parameters of the data is essential for the proper use of this diagnostic technique for studying works of art. The optimization of these parameters allows the location within the volume of possible non-homogeneous parts, fractures or damage. The choice of cell size for the inversion process is very important in obtaining good results. Usually, cell dimensions should be bigger than the expected resolution, calculated using the theory of the Fresnel radius (Cerveny and Soares 1992). However, for picking the first arrivals it is fundamental to establish the frequency of their ramps. Since the modulation of a monochromatic signal by a pulse causes much higher frequencies than those of the original one (i.e. the transmitting probe, $55 \mathrm{kHz}$ ), we calculate the lateral resolution using the maximum frequency of the ramp of the first arrivals, which in many cases is practically determined by the sampling frequency of the signal. The interpretative ultrasonic model was then finally compared with the results of a groundpenetrating radar (GPR) survey.

GPR is a method commonly used for non-destructive subsurface imaging (Conyers 2004, Daniels 2004). The detection of buried objects or discontinuities with a GPR is not simple as very few discontinuities within the investigated medium give return signals (Daniels 2004, Radzevicius et al 2000, Sambuelli et al 2011). Several studies have also been conducted to detect and locate subsurface fractures, and all of them showed that GPR can give good results (Grandjean and Goury 1996, Rashed et al 2003, Pérez-Gracia et al 2009, Bavusi et al 2010). A procedure which we implemented in the Matlab environment was used to calculate depth slices, choosing the appropriate parameters and analysis window, depending on the shape, size and location of the anomalies detected with ultrasonic and covermeter surveys.

\section{Ultrasonic tomography}

To study the structural continuity of the material, a highresolution $3 \mathrm{D}$ ultrasonic tomography was chosen.
Ultrasonic measures have been carried out using the TDAS 16 Boviar multichannel system, which acquires up to 16 channels using an electronic switch on four channels at a time with a maximum sampling rate of $1.25 \mathrm{MHz}$. The equipment is supplied with receiver and transmitter probes characterized by a central frequency of $55 \mathrm{kHz}$. Considering a marble velocity of about $3200 \mathrm{~m} \mathrm{~s}^{-1}$ and the central frequency of the probes $(55 \mathrm{kHz})$, we obtained a main wavelength of about $0.06 \mathrm{~m}$.

The acquisition was realized using 65 measurement points, 40 distributed on the thickness of the slab side and 25 on the relief (figure 2). The distance between two consecutive probe positions was set to $100 \mathrm{~mm}$ for measurement points distributed on the external thickness of the slab side.

The survey was performed throughout the volume of the slab to avoid leaving unexplored volumes. The coupling between the probe and the surface of the slab was improved using plasticine, which allowed the filling of the interspaces due to the surface roughness.

The traveltimes of elastic waves were measured using a manual picking procedure. Before the inversion procedure, tomographic data were filtered by removing the velocity values lower than $2000 \mathrm{~m} \mathrm{~s}^{-1}$ and higher than $6000 \mathrm{~m} \mathrm{~s}^{-1}$; both of them were considered outliers.

A total of 961 signals were acquired and processed, on which the traveltimes of elastic waves were measured by picking procedures (figure 3 ).

Traveltime data were inverted using the GeoTomCG software, which performs inversions with the simultaneous iterative reconstruction technique (SIRT) (Peterson et al 1985). SIRT calculations modify an initial velocity model by repeated cycles in three steps: forward computation of model traveltimes, calculation of residuals and application of velocity corrections. Curved ray tracing performed with a revised form of ray bending, derived from the method given by Um and Thurber (1987), was used for the inversion process.

Although amplitude information could be a valid support to interpret the velocity analysis (Berryman 1990), data are 


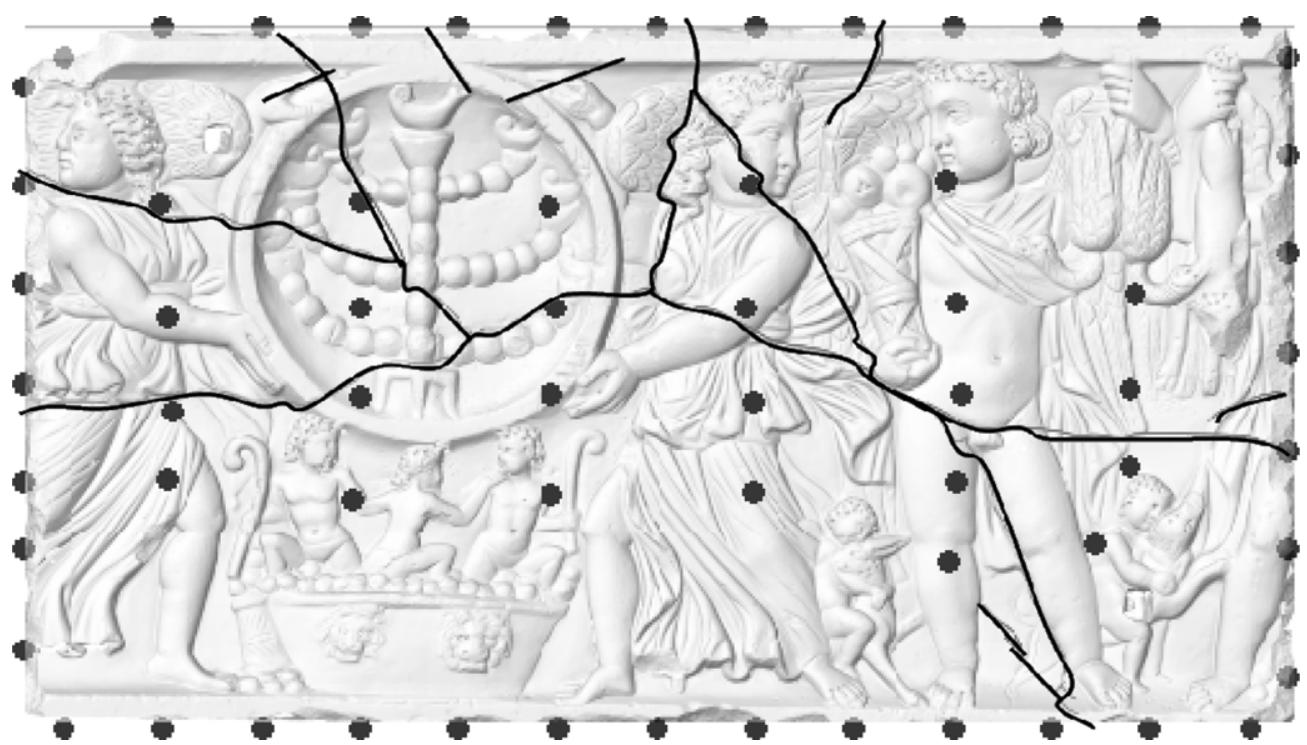

Figure 2. Measurement points (black circles) used for ultrasonic tomography. The black lines denote visible ancient and recent lesions.

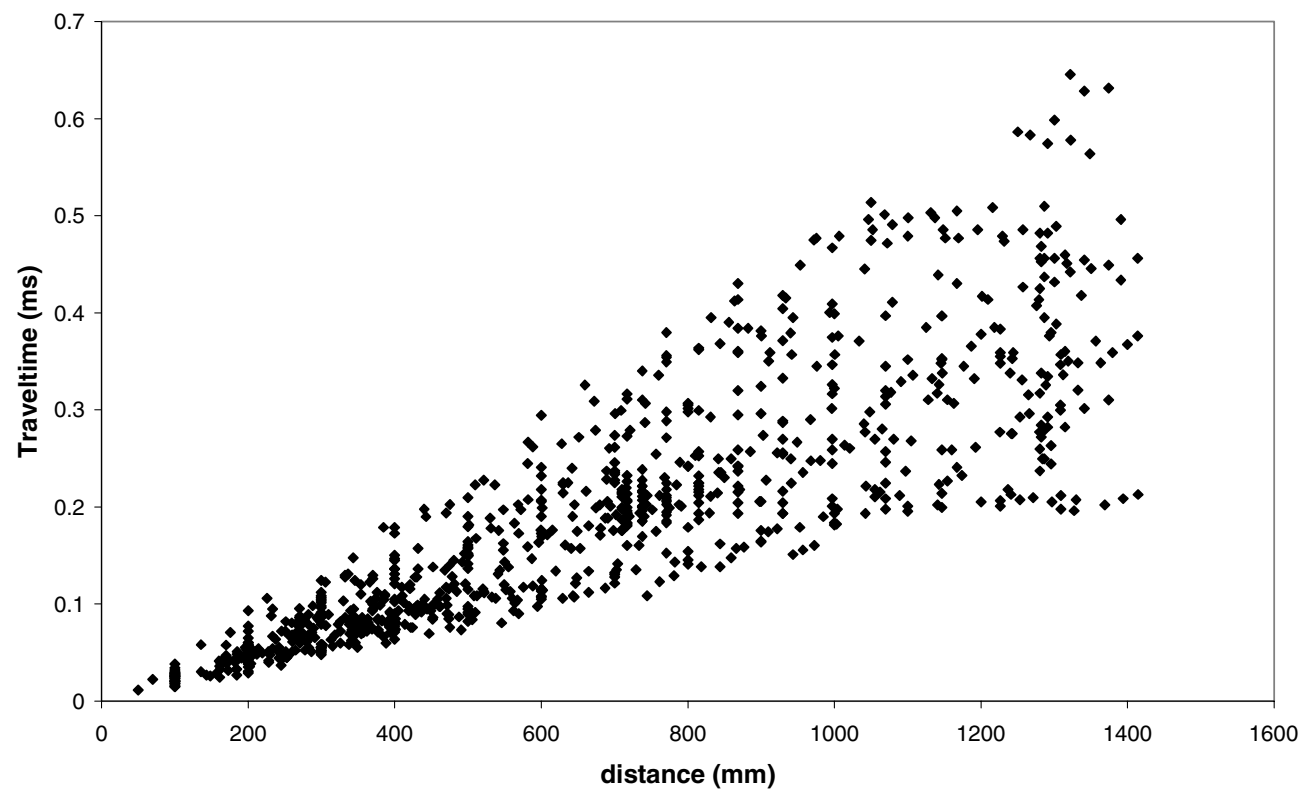

Figure 3. Traveltime graph of acquired data.

often problematic in source and receiver coupling, especially in the presence of an irregular surface, like in our case. For these reasons, we decided to use the acquired data sets only to implement traveltime tomography (i.e. a kinematic analysis).

In principle, for monochromatic waves, lateral resolution should be calculated using the theory of Fresnel radius $r$ (Cerveny and Soares 1992) as

$$
r=\left[(\lambda / 2)^{2}+L \lambda\right]^{1 / 2} \text {. }
$$

Here $L$ is the ray length and $\lambda$ is the wavelength calculated using $\lambda=v / f$, where $v$ is the velocity and $f$ is the frequency of the waves.

However, regarding the lateral resolution obtained by picking the first arrivals of the signals, we have to consider the maximum frequency contained in the ramp. In our experience, this part of the signal contains very high frequencies, much higher than the dominant one, due to the pulse modulation of the source signal. However, the maximum frequency content of the received signal decreases with increasing distance between the source and the receiver.

For the above considerations, we evaluate the lateral resolution with equation (1) but using the highest frequency $\lambda_{\max }$ found in the picking of the first arrivals. The highest frequency contained in the area of the first arrival must be extracted from the digitized signal ramp, and generally depends on the sampling frequency, according to the wellknown rule derived from the Nyquist-Shannon theorem (Grenander 1959, Stiltz 1961). 


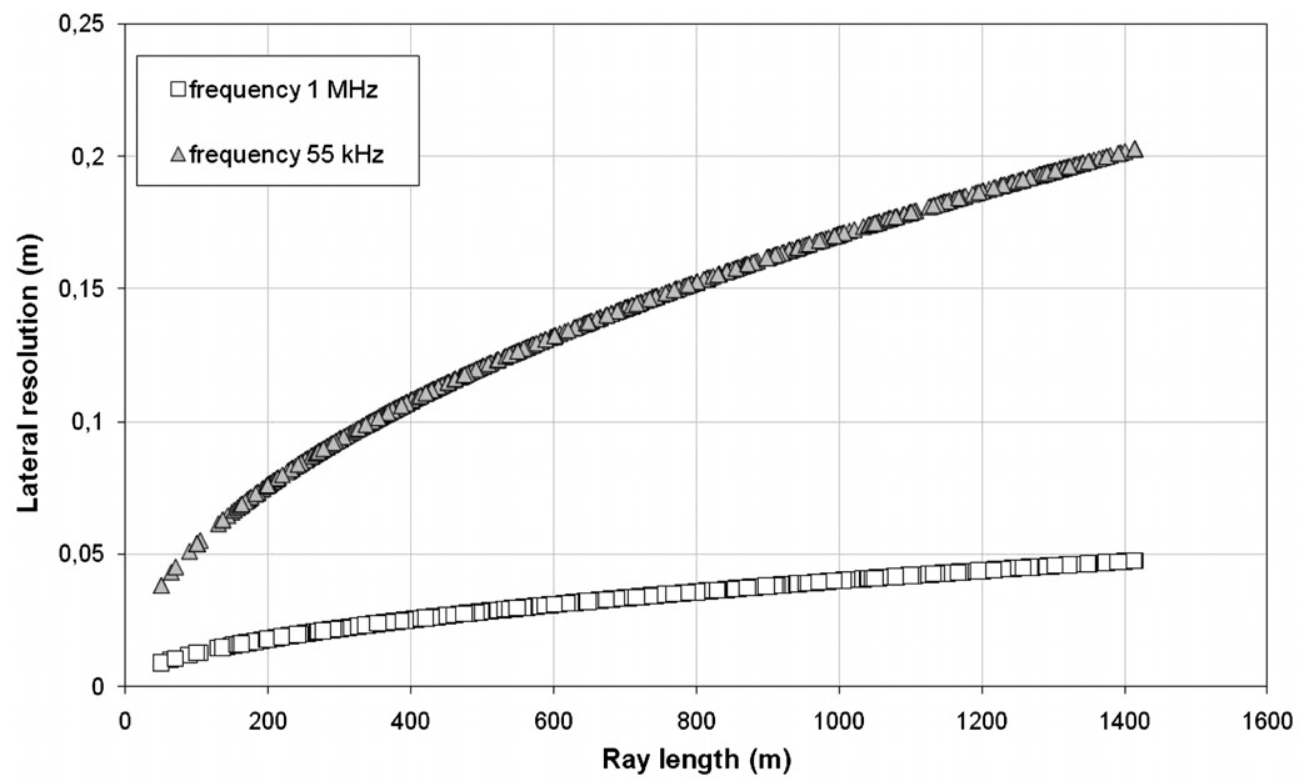

Figure 4. Plot of the lateral resolution versus ray lengths in a material with a velocity of $3200 \mathrm{~m} \mathrm{~s}^{-1}$.

Table 1. Lateral resolution calculated for minimum, maximum and mean paths using the main frequency of probes $(55 \mathrm{kHz})$ and sampling frequency $(1 \mathrm{MHz})$.

\begin{tabular}{llrr}
\hline & Minimum & Mean & Maximum \\
\hline Length path (cm) & 5.0 & 66.5 & 141.4 \\
Lateral resolution (cm)_-55 kHz & 3.8 & 13.2 & 20.2 \\
Lateral resolution $(\mathrm{cm})-1 \mathrm{MHz}$ & 0.8 & 3.2 & 4.7 \\
\hline
\end{tabular}

In figure 4, the lateral resolution, calculated either by the frequency of the probes or by the sampling frequency, is plotted versus the ray lengths, so that it is easy to compare them at various distances.

In table 1, lateral resolution calculated for minimum, maximum and mean paths is shown.

The use of cell dimensions that are too small can result in a tomographic image highlighting possible anomalous rays. For this reason, some tests have been carried out for different cell dimensions, and finally we decided to use a $2 \times 2 \times 2$ $\mathrm{cm}^{3}$ cell size for the inversion process. Figure 5 shows the results for a horizontal $2 \mathrm{D}$ section obtained using different cell dimensions for the inversion process. The $2 \mathrm{D}$ sections are extracted from the 3D model at a depth of 3-4 cm. It is clear that using a big cell size $\left(5 \times 5 \mathrm{~cm}^{2}\right)$ makes the anomalies too smooth, whereas the use of a smaller cell size $\left(2 \times 2 \mathrm{~cm}^{2}\right)$ better locates the anomalies' areas.

The final model shows velocity values with a minimum of about $1500 \mathrm{~m} \mathrm{~s}^{-1}$ and a maximum of about $5000 \mathrm{~m} \mathrm{~s}^{-1}$ (that is probably the velocity of the original marble). This lack of homogeneity and the presence of low velocity values suggest that the state of the marble is poor, especially in correspondence to the injury of the slab (recent or not) as evidenced by the superimposition of a tomographic ultrasonic image on the relief of the slab (figure 6).

\section{The covermeter survey}

The covermeter method allows us to detect and locate metal inserts, mainly metals, in the concrete (or other stones). This type of survey is considered completely nondestructive.

The covermeter system used for measurements is the Elcometer 331 Protovale Mod.SE, which consists of a central unit, a detection antenna and a standard cable-probe. The instrumentation is accompanied by the EDTS Cover Master software for the design phase of the acquired signals. Unlike other covermeters, exploiting the principle of magnetic induction, the system of measurement instrumentation is based on the principle of 'eddy currents', which guarantees stability, precision and repeatability of recordings.

The survey was carried out along an array parallel and perpendicular to the direction of the maximum elongation of the slab. The investigations enabled us to locate some anomalies, probably due to the presence of metal (pins and/or carriers) within the thickness of the slab.

The positioning of anomalies, obtained with the covermeter, was subsequently corrected with the integration of results obtained through GPR surveys (figure 7).

\section{GPR surveys}

GPR surveys were carried out using the Aladdin system (IDS), with a $2 \mathrm{GHz}$ bipolar antenna. The range, i.e. the parameter determining the time of the signal recording, was set to $5 \mathrm{~ns}$ (minimum possible setting for the instrument), but only $2.5 \mathrm{~ns}$ were successively considered for the interpretation, which allowed us to investigate the whole thickness of the marble slab.

It was decided to acquire a top profile in the configuration shown in figure 4 . Considering the direction of the maximum 

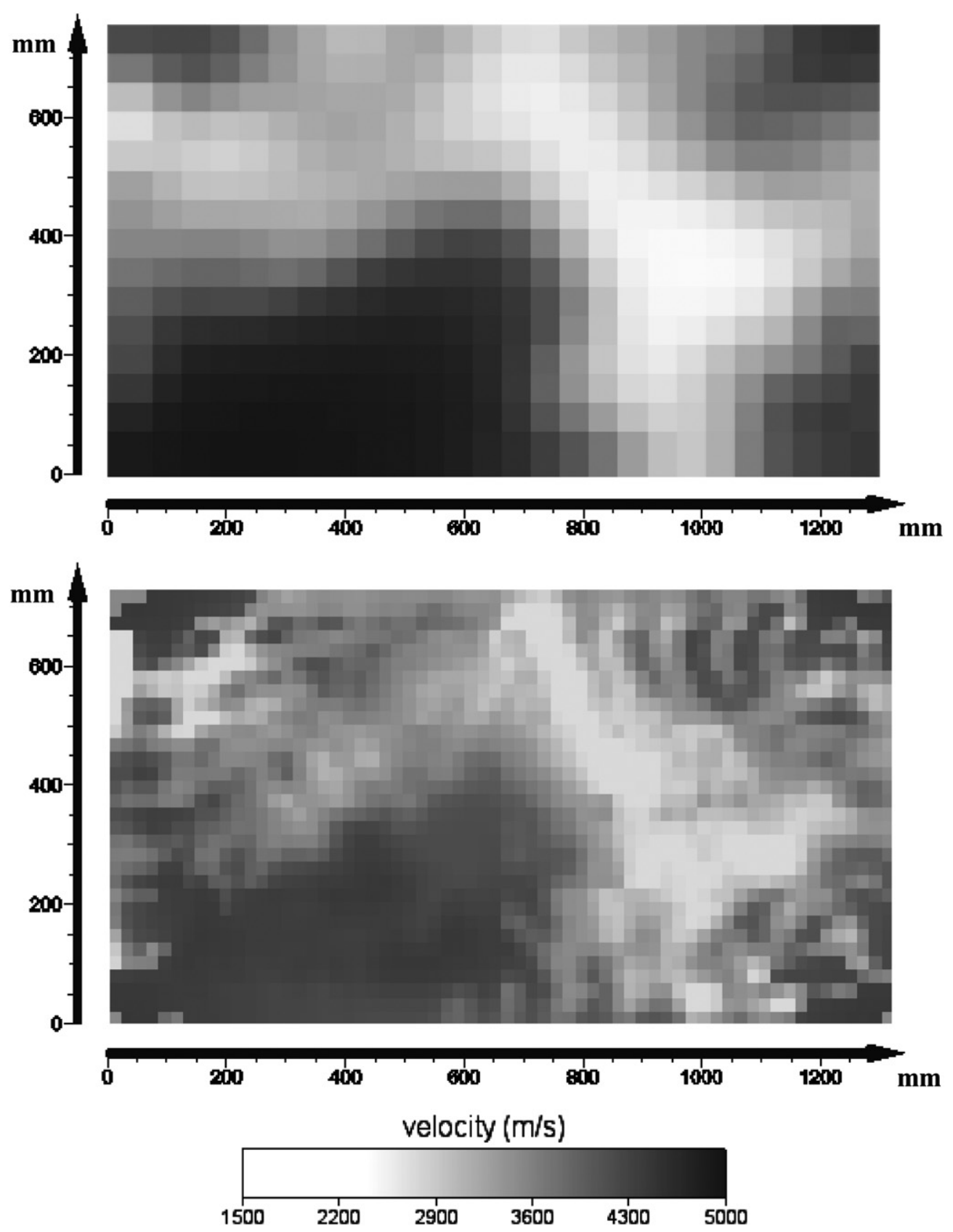

Figure 5. Inversion results obtained for the same $2 \mathrm{D}$ tomographic section, using $5 \times 5 \mathrm{~cm}^{2}$ (upper) and $2 \times 2 \mathrm{~cm}^{2}$ (bottom) cell dimensions. The white colour indicates anomalous areas.

elongation of the slab, 12 longitudinal and seven transverse profiles were acquired. This configuration allowed us to obtain a good sampling of the data, achieving tomographic images with high detail.

To transform the traveltimes of reflected waves in the depth of the reflectors, we estimated the electromagnetic wave velocity in the marble with some tests in transparency mode with the antenna placed on the opposite sides of the marble slab. The resulting velocity value was $0.06 \pm$ $0.005 \mathrm{~m} \mathrm{~ns}^{-1}$, corresponding to a relative dielectric constant of 25 .

Raw data cannot be interpreted (example in figure 8, top) due to the first reflections hiding everything for about
$2 \mathrm{~ns}$; therefore, the following processes have been carried out with the Sandmeier's software Reflex, using the standard sequence:

- background removal, to eliminate temporally consistent noise from the whole profile and to emphasize signals which vary laterally;

- frequency filter, to suppress noise when it differs from the signal in its frequency content;

- running average, to suppress trace-dependent noise and to emphasize horizontally coherent energy;

- envelope, to obtain a measure of the reflectivity strength, which is proportional to the square root of the complete energy of the signal at an instant of time. 


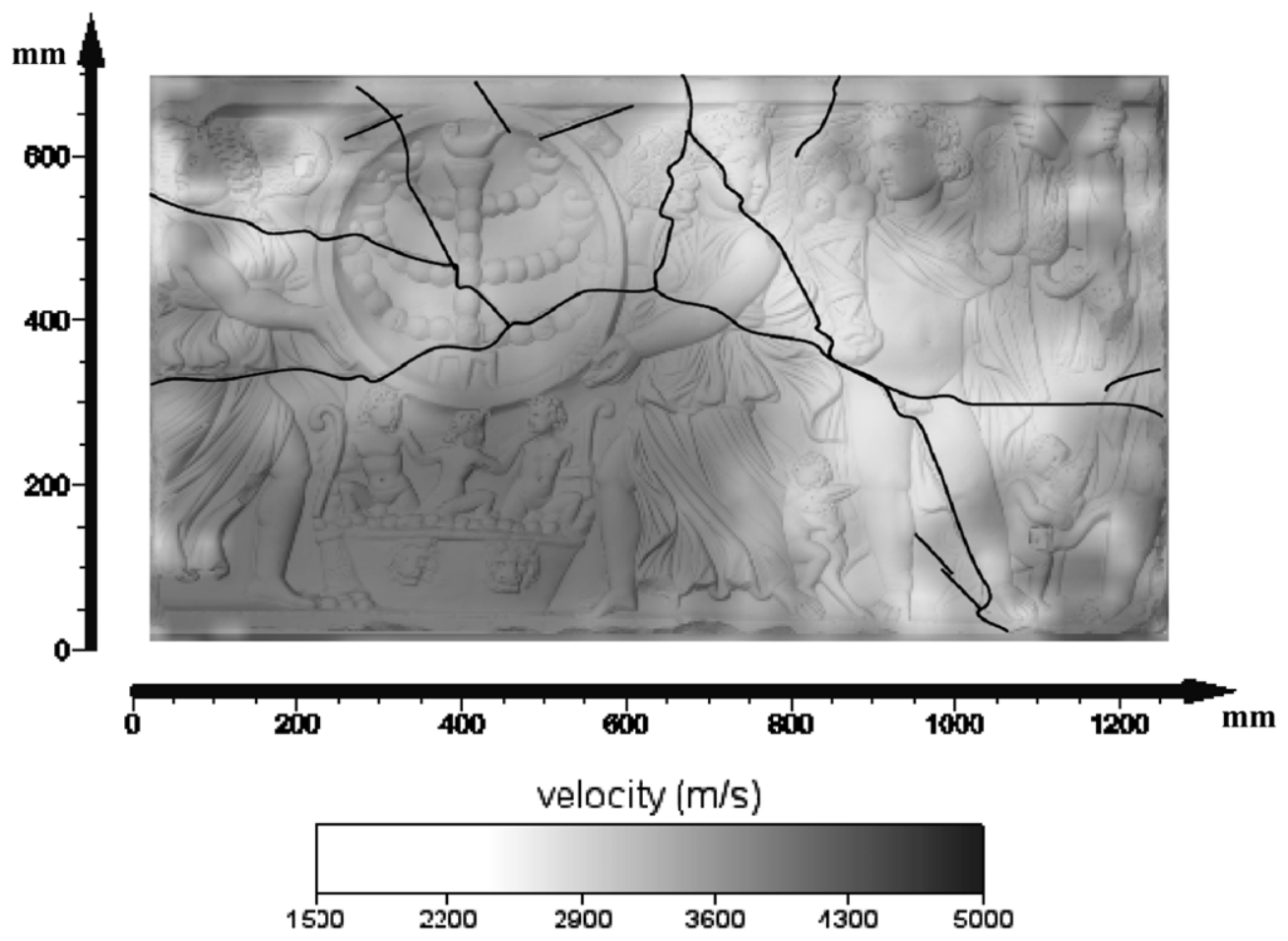

Figure 6. Smoothed 2D tomographic section, using $2 \times 2 \mathrm{~cm}^{2}$ cell dimensions, superimposed onto the slab image.

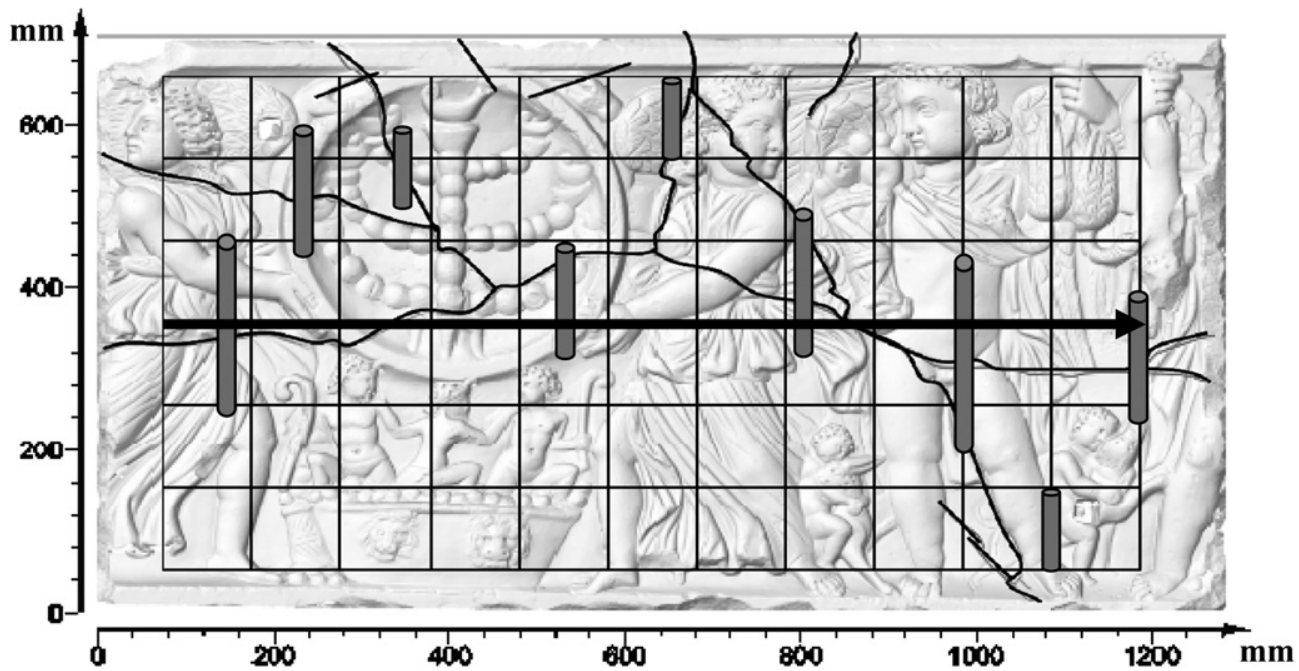

Figure 7. Pin locations (grey bars) obtained by the integration of GPR profiles (along the black lines) and main covermeter anomaly points. The black arrow indicates the GPR profile shown in figure 8.

The same example in figure 8 (top) is presented after processing but not migration in figure 8 (bottom).

The GPR processed data were used to construct depth slices which were calculated using a procedure implemented in the Matlab environment. In particular, we chose an analysis window of $0.25 \mathrm{~ns}$ along the time axis and $0.05 \mathrm{~m}$ along the distance axis: the dimensions have been suggested by the shapes, sizes and locations of the main anomalies detected with covermeter and ultrasonic surveys. The depth slice presented in figure 9 corresponds to the central depth $(4-5 \mathrm{~cm})$ of the slab.
The scale of the amplitudes was normalized in the presented map to the maximum value recorded. High amplitude anomalies are related to the presence of the pins, whose presence was also confirmed by covermeter investigations. The detected GPR anomalies correspond to changes in the electromagnetic properties of the material, as well as to metallic elements of reinforcement.

Finally, to study the correlation between GPR and ultrasonic results, an integrated map was constructed (figure 10). This map has been obtained using the normalized 

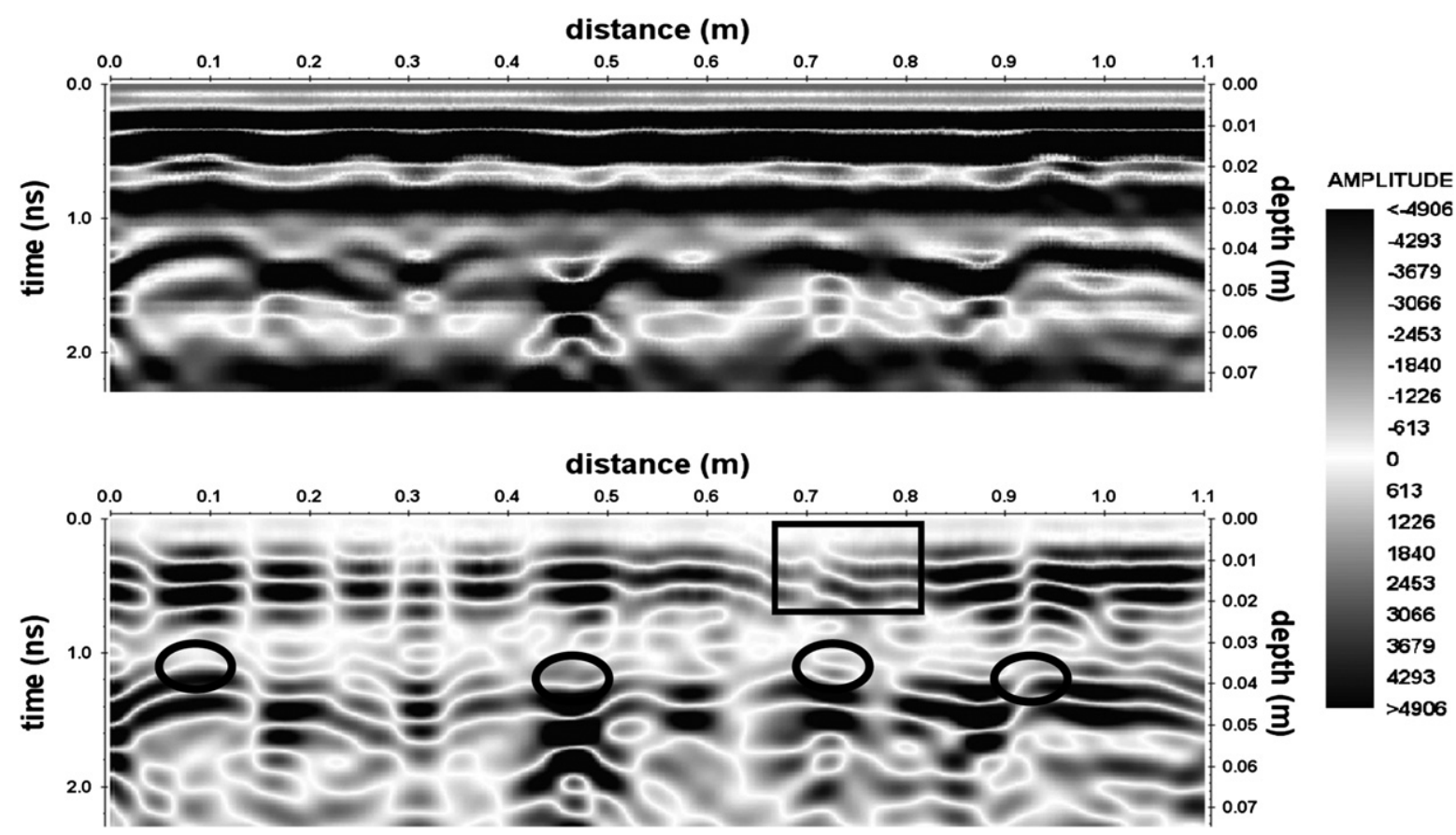

Figure 8. Example of a GPR profile, with the raw data (above) and processed (below). The black circles indicate pin locations obtained by integration with covermeter anomalies. The black square locates the fracture areas.

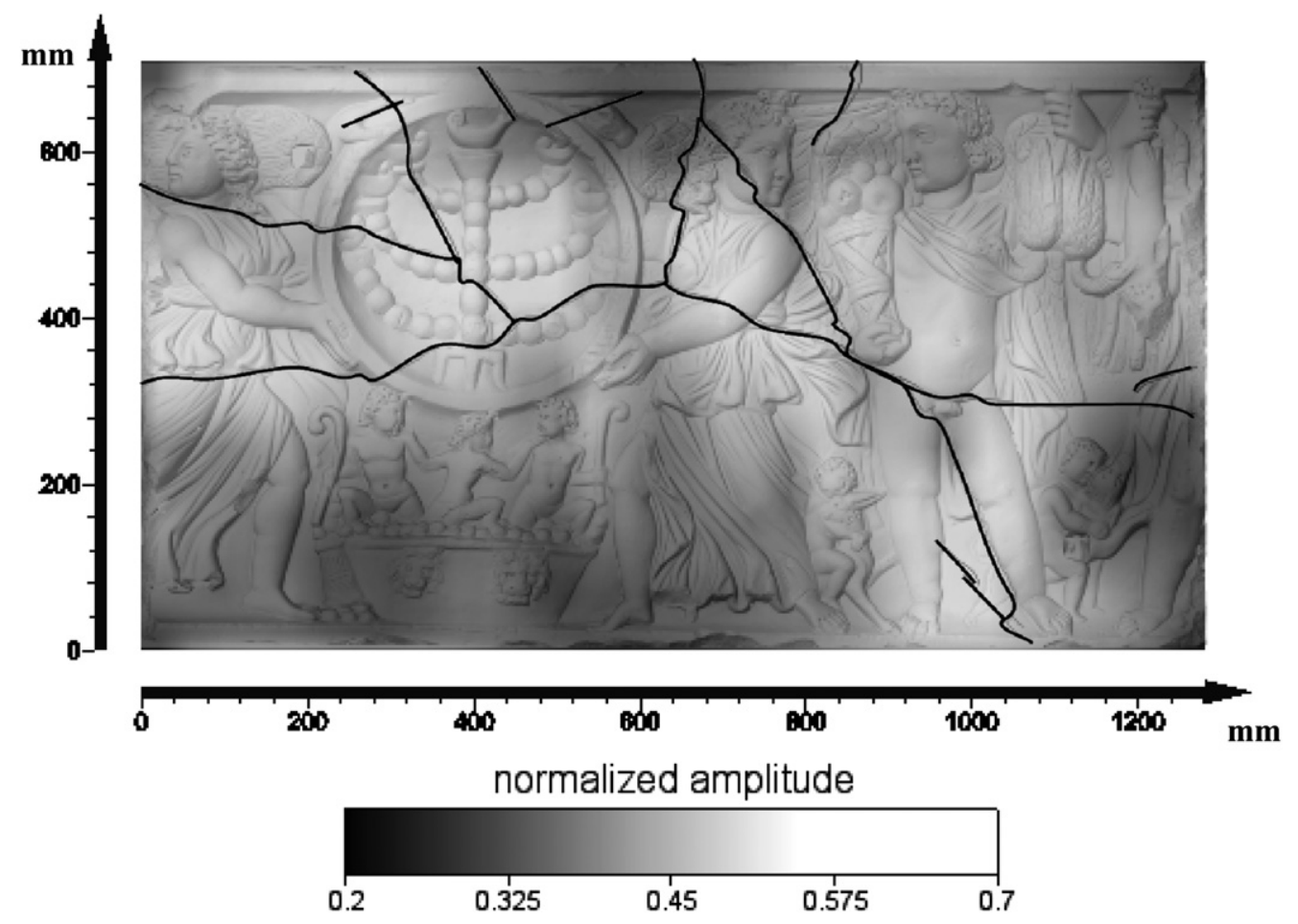

Figure 9. 2D GPR tomography superimposed onto the slab image. The white colour indicates the anomalous areas.

ratio between the GPR amplitude and the ultrasonic velocity at the various points of the map.

It is possible to observe different areas characterized by different values of the ratio but that are homogeneous: they denote that the ratio is different depending on the status of the rock, but the space behaviour of the areas is very similar in the three maps (figures 6, 9 and 10). Obviously, the most degraded areas are characterized by low US velocity values and high GPR amplitudes (probably more diffractions than reflections). 


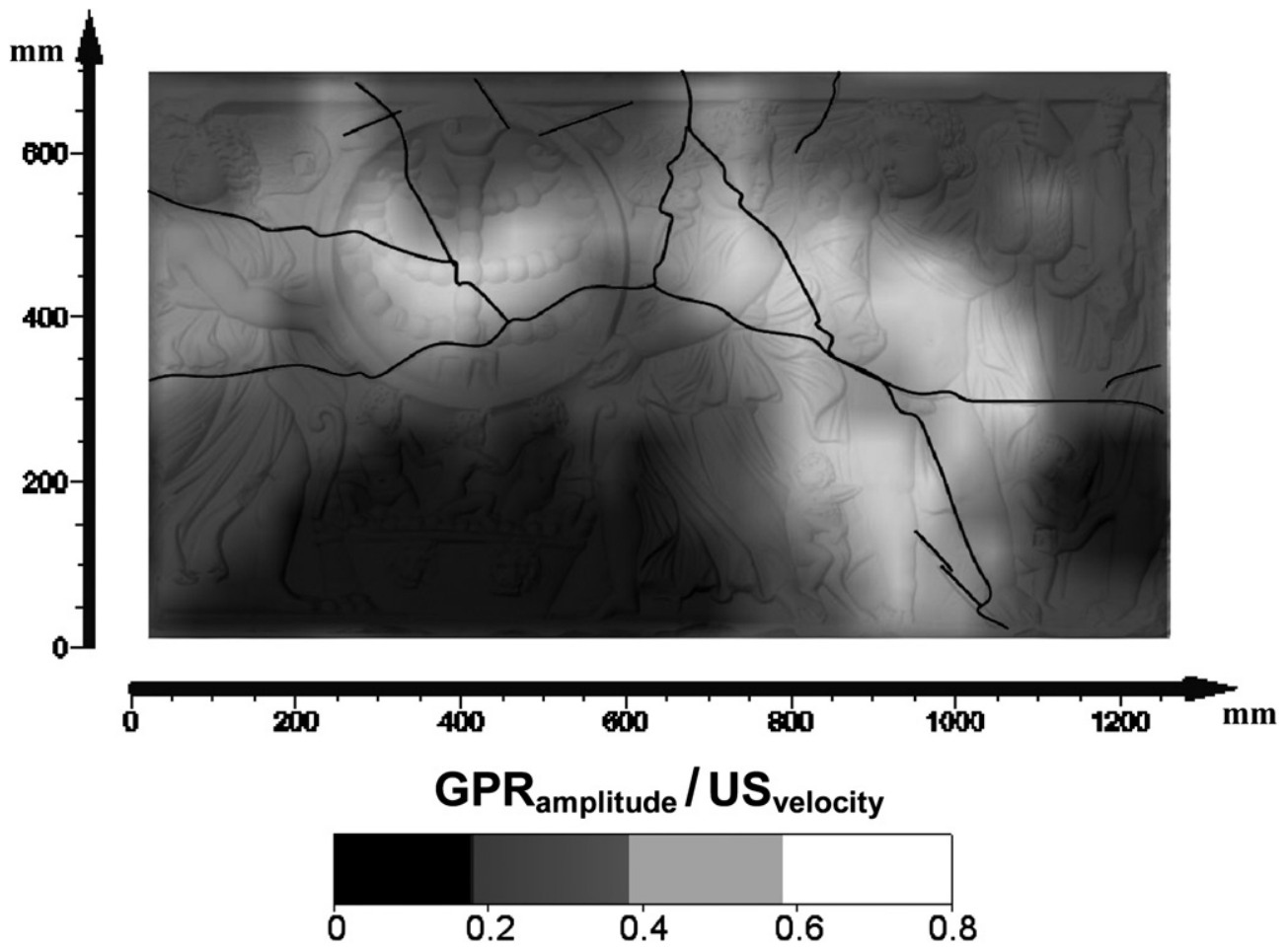

Figure 10. Integrated map of the GPR amplitudes and ultrasonic velocities. The map shows different quasi-homogeneous areas, characterized by the different values of the GPR to US ratio.

\section{Conclusions}

This study has shown the benefits of integrating different methods for a better characterization of an investigated object. Furthermore, the inversion of ultrasonic data was carried out using cells smaller than the expected resolution. Indeed, the frequency analysis of the signal at first arrival confirmed that the signal is also characterized by very high frequencies that can be well detected using an appropriate sampling rate. Therefore, the sampling frequency, within certain limits, can be considered as an estimate of the maximum frequency detected in the signal and can be used to calculate a sort of minimum radius of Fresnel connected with the first arrival pulse.

Finally, information obtained from the ultrasonic and covermeter surveys allowed a best choice of analysis window to calculate depth slices.

As regards the results given to the museum, we can confirm that the slab is in bad condition with reduced physical and mechanical characteristics. The fall of the marble slab caused a weakening of the marble and a deterioration of its mechanical properties, as existing lesions and the development of new lesions practically cover the whole slab. The damage caused to the material is not easily remediable because it is not possible to reconstruct the characteristics of the material before undergoing such a trauma. In this condition the slab cannot be raised without risk of further damage. Furthermore, the possibility of inserting new pins into the stone, whose structure is already severely damaged, was excluded. For these reasons, a steel containment belt with reversible support was developed, allowing the artwork to be admired from both the front and back. In addition, a suitable consolidation project can be planned to reinforce the whole marble structure.

\section{Acknowledgments}

The authors wish to thank the Dart Laboratory (Silvia Gambardella and C. snc) for the opportunity to use the 3D topographic relief of the slab, and Gianluca Fiandaca for his help in data acquisition.

\section{References}

Asakawa E and Kawanaka T 1993 Seismic ray tracing using linear travel time interpolation Geophys. Prospect. 41 99-111

Bavusi M, Soldovieri F, Piscitelli S, Loperte A, Vallianatos F and Soupios P 2010 Ground-penetrating radar and microwave tomography to evaluate the crack and joint geometry in historical buildings: some examples from Chania, Crete, Greece Near Surf. Geophys. 8 377-87

Berryman G 1990 Stable iterative reconstruction algorithm for nonlinear traveltime tomography Inverse Problems 6 21-42

Binda L, Saisi A, Tiraboschi C, Valle S, Colla C and Forde M 2003 Application of sonic and radar tests on the piers and walls of the Cathedral of Noto Constr. Build. Mater. 17 613-27

Blitz J and Simpson G 1996 Ultrasonic Methods of Non-destructive Testing Series (Springer) p 280

Capizzi P, Cosentino P L, Martorana R, Razo Amoroz I, Riela S, Rizzari G and Schiavone S 2009 Indagini geofisiche a supporto dell'intervento di restauro di Palazzo Branciforte (Palermo) Atti del convegno Lo Stato dell'Arte 7-IGIIC (Napoli) 7 pp 121-8

Cardarelli E and De Nardis R 2001 Seismic refraction, isotropic anisotropic seismic tomography on an ancient monument (Antonino e Faustina temple AD 141) Geophys. Prospect. 49 228-40 
Cerveny V and Soares J E P 1992 Fresnel volume ray tracing Geophysics 57 902-15

Conyers L B 2004 Ground-Penetrating Radar for Archaeology (Walnut Creek, CA: AltaMira Press) p 224

Daniels D J 2004 Ground Penetrating Radar 2nd edn (London: Institution of Electrical Engineers IEE Press) p 726

Dynes K A and Lytle R J 1979 Computerized geophysical tomography Proc. IEEE 67 1065-73

Grandjean G and Goury J C 1996 GPR data processing for 3D fracture mapping in a marble quarry (Thallos, Greece) J. Appl. Geophys. 36 19-30

Grenander U 1959 Probability and Statistics (New York: Wiley) p 434

Pérez-Gracia V, Caselles O, Clapés J, Osorio R, Canas J A and Pujades L G 2009 Radar exploration applied to historical buildings: a case study of the Marques de Lliò Palace, in Barcelona (Spain) Eng. Fail. Anal. 16 1039-50

Peterson J E, Paulson B N P and McEvilly T V 1985 Applications of algebraic reconstruction techniques to crosshole seismic data Geophysics 50 1566-80
Phillips W S and Fehler M C 1991 Traveltime tomography: a comparison of popular methods Geophysics 56 1639-49

Radzevicius S J, Guy D E and Daniels A J 2000 Pitfalls in GPR data interpretation: differentiating stratigraphy and buried objects from periodic antennae and target effects Geophys. Res. Lett. 27 3393-6

Rashed M, Kawamura D, Nemoto H, Miyata T and Nakagawa K 2003 Ground penetrating radar investigations across the Uemachi fault, Japan J. Appl. Geophys. 53 63-75

Sambuelli L, Bohm G, Capizzi P, Cardarelli E and Cosentino P 2011 Comparison among GPR measurements and ultrasonic tomographies with different inversion algorithms. An application to the basement of an ancient Egyptian sculpture J. Geophys. Eng. $8 \mathrm{~S} 106$

Santamarina J C and Fratta D 1998 Introduction to Discrete Signals and Inverse Problems in Civil Engineering (Reston, VA: ASCE Press) p 327

Stiltz H L 1961 Aerospace Telemetry (Englewood Cliffs, NJ: Prentice-Hall) $505 \mathrm{pp}$

Um J and Thurber C 1987 A fast algorithm for two-point seismic ray tracing Bull. Seismol. Soc. Am. 77 972-86 